\title{
Molecular Characterization of Plasmid pMbo4.6 of Moraxella bovis ATCC 10900
}

\author{
Beata Furmanek-Blaszk • Natalia Kurpiewska • \\ Robert Boratynski · Marian Sektas
}

Received: 30 July 2012/ Accepted: 10 October 2012/Published online: 6 November 2012

(C) The Author(s) 2012. This article is published with open access at Springerlink.com

\begin{abstract}
We report the characterization of a small cryptic plasmid unlike any previously described from Moraxella bovis ATCC 10900, a Gram-negative bacterium belonging to the family Moraxellaceae. The complete nucleotide sequence of the plasmid pMbo4.6 was determined. The plasmid was analyzed and found to be 4658 in size with a $\mathrm{G}+\mathrm{C}$ content of $38.6 \mathrm{~mol} \%$. Computer analysis of the sequence data revealed four major open reading frames encoding putative proteins of 10.1 (ORF1), 64.2 (ORF2), 45.7 (ORF3), and $12.1 \mathrm{kDa}$ (ORF4). ORF1 and ORF2 encode proteins that show a high level of amino acid sequence similarity (44\%) with some mobilization proteins. ORF3 encodes a protein showing a relatively high amino acid sequence similarity (about $40 \%$ ) with several plasmid replication initiator proteins. Upstream of ORF3, a 320-bp intergenic region, constituting the putative origin of replication that contained an AT-rich region followed by four direct repeats, was identified. This set of repeated sequences resembles iteron structures and plays an important role in the control of plasmid replication by providing a target site for the initiation of transcription and replication factors (IHF and RepA). Several palindromic sequences, inverted repeats, and hairpin-loop structures, which might confer regulatory effects on the replication of the plasmid, were also noted. ORF4 encodes an uncharacterized protein, conserved in bacteria, belonging to the DUF497 family. Sequence analysis and structural features indicate that pMbo4.6 replicates by a theta mechanism.
\end{abstract}

B. Furmanek-Blaszk $(\bowtie) \cdot$ N. Kurpiewska $\cdot$ R. Boratynski .

M. Sektas

Department of Microbiology, University of Gdansk, Kladki 24,

80-822 Gdansk, Poland

e-mail: furmanek@biotech.ug.gda.pl

\section{Introduction}

Moraxella bovis is the bacterial agent most frequently isolated in acute and chronic cases of infectious bovine keratoconjunctivitis (IBK) [17]. This organism is rod-shaped, Gram-negative, oxidase-positive and nonmotile. The ability to cause IBK is associated with the production of a certain virulence factor. Plasmids may specify a variety of factors that enhance survival or virulence in pathogenic bacteria. The factors mediated by these plasmids include antibiotic resistance, adhesions, hemolysins and exotoxins. The majority of $M$. bovis strains are known to contain multiple plasmids ranging from 4 to $45 \mathrm{~kb}$ in size, but no relationships between the number of plasmids and virulence has been found $[23,28]$. In fact, there have only been a few previous reports of plasmids being isolated from $M$. bovis and only one plasmid (pMBO-1) has currently been characterized. In 2006 Kakuda et al. [20] showed that M. bovis Epp63 contains a 44.2-kb plasmid pMBO-1 carrying two large ORFs, $f p A$ and $f p B$, encoding proteins with similarity to Bordetella pertusis filamentous haemagglutinin. This strain also contains a 27-kb plasmid pMBO-2 which encodes several proteins involved in the conjugational transfer of plasmids. The recent discovery and determination of a complete sequence of conjugative and/or mobilizable plasmids and their possible ability for cell-to-cell transmission might be another important factor for the adaptive potential apparent in this group of bacteria [20,34]. It was shown that the large plasmids share some regions of structural similarities indicating possible recombinational changes between them [20,35]. However, there is a strong genetic barrier to interspecies transformation in the moraxellae [19].

This paper presents the complete nucleotide sequence of the pMbo4.6 plasmid of M. bovis ATCC 10900 and genetic analysis of its elements. 


\section{Materials and Methods}

\section{Bacterial Strains and Growth Conditions}

The M. bovis strain ATCC 10900, generously provided by Dr. E Falsen (University of Göteborg, Sweden), was grown routinely on brain-heart infusion agar (BHI), tryptic soy (TS) agar with $5 \%$ sheep blood or TS broth (Graso, Poland) and incubated in air at $37{ }^{\circ} \mathrm{C}$. The Escherichia coli strain DH5 $\alpha$ [15] was used for a routine cloning procedure. The E. coli MC1061 strain [6] was used for the $\beta$-galactosidase expression measurement. The overproduction of the RepA protein was performed with E. coli BL21(DE3) [30]. The E. coli strains were routinely grown and maintained in LB medium at $37{ }^{\circ} \mathrm{C}$ with appropriate antibiotic selection. The genomic DNA of the M. bovis strains, IBA, and T412 were kindly provided by Dr. T. Kakuda (Kitasato University, Japan).

\section{DNA Manipulation Techniques}

Plasmid DNA was extracted from M. bovis and E. coli strains by the alkaline lysis technique [4]. Other molecular biologic procedures were followed as described by Sambrook et al. [27]. All the enzymes were purchased from either Fermentas (Lithuania) or New England Biolabs (USA).

\section{Nucleotide Sequence Analysis}

To determine the complete nucleotide sequence of pMbo4.6, the plasmid was digested with $\mathrm{XmnI}$ and then cloned into the Eco $R V$ site of the pBR322 vector [5]. The derived plasmid was then sequenced on both strands using an automated DNA sequencer (model ABIPRISM 310 Genetic Analyzer; PE Applied Biosystems). Comparison searches through the databases were performed by the BLAST program [1] provided by the National Center for Biotechnology Information. The complete sequence of the plasmid was deposited in GenBank at accession no. GQ998872.

\section{Expression and Purification of the Recombinant Protein}

The pMbo4.6 RepA coding region was amplified from the genomic DNA of $M$. bovis using the primer pair repATG with repTAA (Table 1) containing the NdeI or EcoRI restriction sites, respectively. The PCR product was cloned into pET24a that had been digested with NdeI and EcoRI, yielding plasmid pETrepA. pET24a is a vector that employs a phage $\mathrm{T} 7$ promoter for the expression of cloned genes. The integrity of pETrepA was verified by DNA sequencing before being transformed into $E$. coli BL21(DE3). From a $500 \mathrm{ml}$ culture, cells were harvested, resuspended in $20 \mathrm{ml}$ of buffer $\mathrm{S}$ (10 mM potassium phosphate $\mathrm{pH} 6.5,20 \mathrm{mM}$
$\mathrm{KCl}, 1 \mathrm{mM}$ EDTA, $10 \mathrm{mM}$ 2-mercaptoethanol, $5 \%$ (v/v) glycerol) supplemented with a protease inhibitor $0.1 \mathrm{mM}$ phenyl-methyl-sulfonyl-fluoride and disrupted by sonication at $4{ }^{\circ} \mathrm{C}$ in $60 \times 10$-s bursts. After centrifugation, the supernatant was applied to a $3.5 \times 2.8 \mathrm{~cm}$ phosphocellulose P11 column equilibrated with buffer $S$. The column was then washed with $200 \mathrm{ml}$ of buffer $\mathrm{P}$ and the proteins eluted with a $150 \mathrm{ml} \mathrm{KCl}$ gradient $(20-1000 \mathrm{mM})$ in the same buffer. Fractions of $2 \mathrm{ml}$ were collected and assayed for RepA protein's presence by $10 \%$ SDS-polyacrylamide gel electrophoresis and Coomassie Blue staining.

\section{DNA-Binding Experiments}

Primers were used directly in PCR amplification to generate probes which were purified by electroelution and stored at $-20{ }^{\circ} \mathrm{C}$. The orirep35 probe (nt 2381-2758), the orirep32 probe (nt. 2381-2564), and the orirep15 probe (nt 2573-2658) were generated with the primer pairs: orirep3/ orirep5, orirep3/orirep2, orirep1/orirep5, respectively (Table 1). Electrophoretic mobility shift assays were performed by incubating DNA with increasing amounts of purified RepA protein in a $1 \times$ binding buffer $(10 \mathrm{mM}$ Tris- $\mathrm{HCl} \mathrm{pH}$ 7.5, $10 \mathrm{mM} \mathrm{MgCl}_{2}, 100 \mathrm{mM} \mathrm{NaCl}, 0.2 \mathrm{mM}$ dithiotreitol, and $5 \%(\mathrm{v} / \mathrm{v})$ glycerol) and a final reaction volume of $30 \mu \mathrm{l}$. After incubation at $22{ }^{\circ} \mathrm{C}$ for $20 \mathrm{~min}$, the reaction mixtures were separated on $6 \%$ polyacrylamide gels at $4{ }^{\circ} \mathrm{C}$ using a $0.4 \times$ TBE buffering system.

\section{Construction of the Plasmid for Promoter Analysis}

To analyze the regulation of activity of the repA gene promoter, lacZ ${ }^{+}$reporter plasmid pRS415 was used as the backbone [29]. For the cloning of the PCR-generated DNA fragment containing the oriV region (378 bp), including the promoter of the repA gene, and oligonucleotides orirep3 and orirep5 were used (Table 1), resulting in a pRSori35 plasmid. The second construct pRSplusIR was created as follows: the 59-bp synthetic DNA fragment formed after annealing the megaD and megaG oligonucleotides (Table 1), containing a predicted promoter region with three IR sequences within, was inserted upstream of the promoter-less reporter lac $Z$ gene between the EcoRI and BamHI sites of the reporter vector pRS415. In addition to this, we cloned the non-iteron repA promoter region obtained by annealing the two oligonucleotides prepG and prepD (Table 1) and cloned it into the EcoRI-BamHI digested vector pRS415. The constructed plasmid was designated pRSminusIR. All the resulting plasmids were introduced into the E. coli MC1061 cells containing the RepA-delivering plasmid pACYCaraRep in the L-arabinose inducible manner. This plasmid was constructed by subcloning the $\operatorname{araC}-P_{\mathrm{araBAD}}: r e p A \mathrm{DNA}$ fragment from the 
Table 1 Primers

\begin{tabular}{lll}
\hline Primer & Sequence $\left(5^{\prime}-3^{\prime}\right)^{\mathrm{a}}$ & Restriction enzyme \\
\hline orirep1 & CTAGGAGGGATTGACTACCAAA & EcoRI \\
orirep2 & CGCAAACCTTTGATACATAAGGC & Bam HI \\
orirep3 & AAGAATTCGGGCGTGGTTTGGGGATTG & NdeI \\
orirep4 & GTGCTTTTTCGGTTTTGGCG & EcoRI \\
orirep5 & TTGGATCCTACAATTAAATCTTTGCTC & \\
orirep6 & CGCCAAAACCGAAAAAGCAC & \\
repATG & GACCTACATATGAGCAAAGATTTAATTG & \\
repTAA & TAAGAATTCCATTAGATATCCAAAA & \\
prepG & AATTCATTTACAATAACTCTTTTTACTCGTATAATTAATTAG & \\
prepD & GATCCTAATTAATTATACGAGTAAAAAGAGTTATTGTAAATG & \\
megaG & AATTCTAGGAGTATTTACAATAACTCTTTTTAGGTGTATAATTAATTACTCCTTTTTTG \\
megaD & GATCCAAAAAAGGAGTAATTAATTATACACCTAAAAAGAGTTATTGTAAATACTCCTAG & \\
\hline
\end{tabular}

${ }^{a}$ Nucleotides that are underlined denote engineered restriction endonuclease sites

pBAD24 derivative [14] into the ClaI-HindIII sites of pACYC177 [7].

$\beta$-Galactosidase Assay

E. coli MC1061 cells bearing pRS415 derivatives and the RepA-delivery plasmid pACYCaraRep were grown at $37{ }^{\circ} \mathrm{C}$ in LB medium with aeration. The media were supplemented with the appropriate antibiotics and with $\mathrm{L}$-arabinose for the induction of the repA gene expression, as indicated. The cells (0.1-ml culture aliquots) were permeabolized with $25 \mu$ of $0.1 \%$ sodium dodecyl sulfate and $50 \mu \mathrm{l}$ of chloroform. Samples were equilibrated at $28{ }^{\circ} \mathrm{C}$ and assayed for a level of $\beta$-galactosidase produced from the fusion $l a c Z^{+}$gene. The reaction was started using $0.2 \mathrm{ml}$ ONPG substrate $\left(4 \mathrm{mg} \mathrm{ml}^{-1}\right)$ until a yellow color developed, and then was stopped by the addition of $0.5 \mathrm{ml}$ of $1 \mathrm{M} \mathrm{Na}_{2} \mathrm{CO}_{3}$. Units were determined by the following equation: $\mathrm{OD}_{420} / \mathrm{OD}_{600} \times$ volume assayed $(\mathrm{ml}) \times \mathrm{min}$, as described [24].

\section{Results}

Sequence Analysis of pMbo4.6

The plasmid pMbo4.6 isolated from M. bovis ATCC 10900 was subcloned and fully sequenced as follows. pMbo4.6 was linearized with $\mathrm{Xmn} I$ and cloned into the $\operatorname{Eco} R V$ site of pBR322 to construct pMbo9.2. The complete nucleotide sequences of both strands of pMbo4.6 were determined (GenBank Accession No. GQ998872). The G+C content of this plasmid was found to be $38.6 \mathrm{~mol} \%$, which is similar to those of plasmids pMBO-1 and pMBO-2 of $M$. bovis Epp63 [20]. Computer analysis of the sequence of
pMbo4.6 revealed the presence of four open reading frames encoding putative proteins of 10.1 ORF1 (MobC), 64.2 ORF2 (MobA), 45.7 ORF3 (RepA), and 12.1 kDa ORF4 (DUF497), which together covered $73 \%$ of the plasmid DNA. ORF2 and ORF3 were in the same transcriptional orientation and ORF1 and ORF4 in the reverse strand. A schematic representation of plasmid pMbo4.6 is shown in Fig. 1a.

To attribute functions to the deduced products of the ORFs, these were compared to the gene products available in the databases. Thus, ORF1 (the mobC gene) contains $276 \mathrm{bp}$ and is found between coordinates 242 and 517 . The putative promoter was recognized upstream of $m o b C$ (578 TTTACG17nt-TATAAT ${ }_{550}$ ) [16]. The MobC protein shares 46 and $44 \%$ identity with the putative mobilization proteins encoded in plasmids pColE9-J (RefSeq Accession NC_011977) and pO26-S4 (NC_011228) from E. coli, respectively. The $m o b A$ gene which starts with an ATG codon is located between coordinates 733-2409 and encodes a protein of 558 amino acids with a predicted molecular weight of $64.2 \mathrm{kD}$. The deduced amino acid sequence exhibits a high level of identity with some plasmid mobilization proteins. The highest similarities between the translational product of ORF2 and other proteins were observed for the TraA protein of plasmid pSmeSM11a (GenBank Accession No. DQ145546) from Sinorhizobium meliloti and the Mob proteins of plasmids p2ABSDF (RefSeq Accession NC_010396) and p3ABSDF (NC_010398) from Acinetobacter baumanii (46\% identity). Both proteins belong to the MobA/MobL family known to be engaged in the conjugal transfer of plasmid DNA. A sequence comparison of the various Mob proteins showed that the highest similarities between these proteins were observed in their $\mathrm{N}$-terminal parts. These conserved sequences correspond to the catalytic domain involved in DNA cleavage-joining 
Fig. 1 Genetic structure of pMbo4.6 plasmid. a Partial restriction map of the plasmid. The location of the mobilization proteins, the replication protein and the DUF497 protein are indicated. b Nucleotide sequence of the putative oriV region. The fragment includes the AT-reach region, IHF binding site, 4 directed repeats (DR, iterons; solid lines under sequence), 9 inverted repeats (IR, arrows between sequence strands), and -35 and -10 boxes of the repA gene promoter. Thin black arrows (above and below) represent the positions and orientations of the various primers (specified in Table 1) used in generating PCR products. Sequence numbering according to the pMbo4.6 sequence deposited at GenBank (Accession No. GQ998872). c Alignment of the oriV regions of the pMbo4.6 and p3ABSDF (CU468233), pABIR (EU294228), p2ABSDF

(CU468232), pAC63

(JN982951), pMMD

(GO904226, pMMCU2

(GQ476987), pMMCU1

(GQ342610), pAB02

(AY228470) Acinetobacter plasmids. Asterisks indicate identical nucleotides. The numbers at the left and right sides of each sequence refer to the deposited nucleotide sequence. Sequences were aligned by CLUSTAL W [31]
A

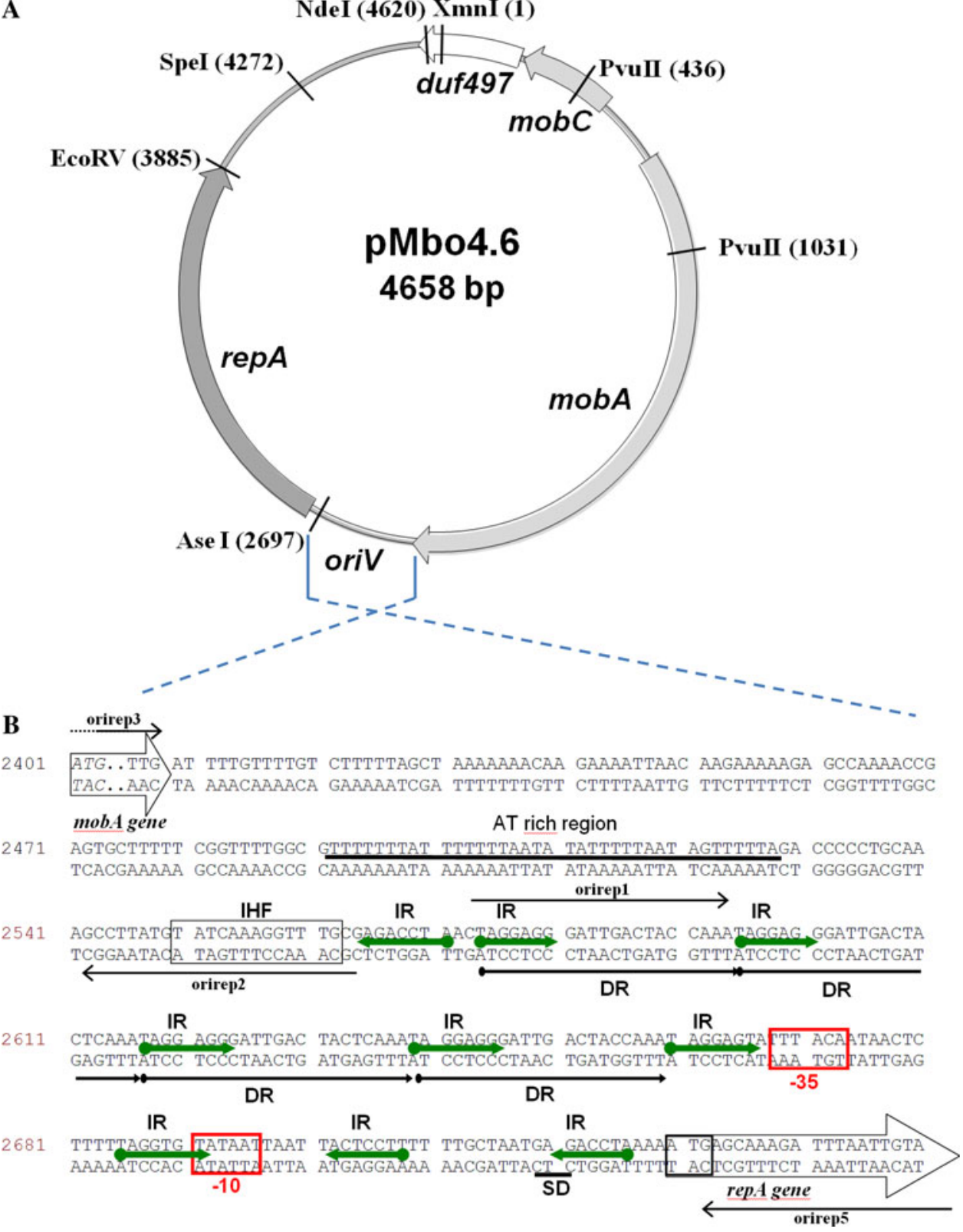

activity. Sequence analysis of the protein encoded by the mobA gene reveals the presence of three conserved motifs which have been used to classify pMbo4.6 into the $\mathrm{MOB}_{\mathrm{Q}}$ family relaxases (the catalytic Tyr in Motif I, conserved Glu in Motif II, and the three His in the 3H Motif III) [11].

Examination of the DNA sequence upstream of the mobA gene for possible promoter sequences reveals a 43-bp DNA fragment nearly identical $(91 \%)$ to the promoter region of the $m o b C$ gene associated with the mobilizable plasmid pEMCJH03 from Moraxella catarrhalis [18]. The DNA sequence between ORF1 and ORF2 may serve as the origin of the conjugal DNA transfer. There is a palindromic sequence with a 9-bp inverted repeat interrupted by the sequence CAA. This inverted repeat may be the structural elements that function as a recognition site for mobilization proteins. MobC acts together with MobA to form a complex called the relaxosome [11].

The entire nucleotide sequence between coordinates 2730 and 3890 (ORF3) encodes a protein showing a relatively high amino acid sequence similarity with several plasmid replication proteins. The RepA protein shares a $50 \%$ identity in its $254 \mathrm{~N}$-terminal domain, with the putative replication protein encoded in plasmid p2ABSDF from Acinetobacter baumanii SDF [32] and $38 \%$ identity with the RepA protein of plasmid pMBO-1 from M. bovis Epp63 [20] (Fig. 2). Moreover, the sequence analysis of the proteins mentioned above revealed the presence of the N-terminal leucine zipper motif. A possible promoter for this 
Fig. 1 continued

\section{C}

PMMCU1

PABO2

PMMD

pAC 63

PMMCU2

PABIR

P2ABSDF

P3ABSDF

pMbo 4.6

DMMCU1

pAB02

PMMD

pAC63

PMMCU2

PABIR

P2ABSDF

P3ABSDF

pMbo 4.6
DR1

DR2

(7739)

(3945)

(7690)

(4472)

(8632)

(215)

(347)

(16732)

(2567)

\begin{tabular}{|c|c|}
\hline & \\
\hline GTTTAACFATGACGGATTGA-------CTACTAAC & PATGACGGATTGACTACT-AACГAT \\
\hline GTTTAACEATGACGGATTGA------CTACTAAC & PATGACGGATTGACTACT-AACFAT \\
\hline GTTTAACEATGACGGATTGA------CTACTAAC & PATGACGGATTGACTACT-AACFAT \\
\hline GTTTAACFATGACGGATTGA-------CTACTAAC & PATGACGGATTGACTACT-AACFAT \\
\hline GTTTAACTATGACGGATTGA-------СТАCTAAC & PATGACGGATTGACTACT-AACFAT \\
\hline GTCTAACEATGACGGATTGA------CTACTAAC & PATGACGGATTGACTACT-AACFAT \\
\hline TTAAC|ATGACGGATTGAGGATTGACTACTAAC & PATGACGGATTGACTACT-AACFAT \\
\hline TTAAATATGAGGGATTGA------CTACTAAC & PATGAGGGATTGACTACT-AACFAT \\
\hline$----\mathrm{CTACCA}$ & AGGAGGGATTGACTACTCAAALAG \\
\hline
\end{tabular}

DR3

DR4

GACGGATTGACTACTTAACFATGACGGATTGACTACTAACTATGACAAGTATATAGTTGT $\quad(7850)$ GACGGATTGACTACTTAACPATGACGGATTGACTACTAACEATGACAAGTATATAGTTGT GACGGATTGACTACTTAACPATGACGGATTGACTACTAACPATGACAAGTATATAGTTGT (7801) GACGGATTGACTACTTAACFATGACGGATTGACTACTAACTATGACAAGTATATAGTTGT (4361) GACGGATTGACTACTTAACPATGACGGATTGACTACTAACEATGACAAGTATATAGTTGT (8521) GACGGATTGACTACTTAAC PATGACGGATTGACTACCAAATATGACAAGTATATATTTGT GACGGATTGACTACTTAACPATGACGGATTGACTACTAACEATGACAAGTATATATTTGT GAGGGATTGACTACTTAACFATGAGGGATTGACTACTAACEATGAGAGAATTATAGTACT (16592) GAGGGATTGACTACTCAAA AAGGAGGGATTGACTACCAAATAGGAGTATTTACAATAACT (2679)
Fig. 2 Comparison of the amino acid sequences of the Rep proteins. The numbers on the right indicate the amino acid position relative to the $\mathrm{N}$-terminus. Identical residues are indicated by an asterisk; two dots denote a highly conservative substitution, one dot a conservative substitution. Sequences were aligned by CLUSTAL W [31]

\section{Rep pMbo4.6 Rep pMBO-1 Rep p2ABSDF \\ Rep pMbo4.6 Rep pMBO-1 Rep p2ABSDF \\ Rep pMbo4.6 Rep pMBO-1 Rep p2ABSDF}

Rep pMbo4.6 Rep pMBO-1 Rep p2ABSDF

Rep pMbo4.6 Rep $\mathrm{pMBO}-1$ Rep p2ABSDF

Rep pMbo4.6 Rep $\mathrm{pMBO}-1$ Rep p2ABSDF

Rep pMbo4.6 Rep pMBO-1 Rep p2ABSDF

Rep pMbo4.6 Rep pMBO-1 Rep p2ABSDF

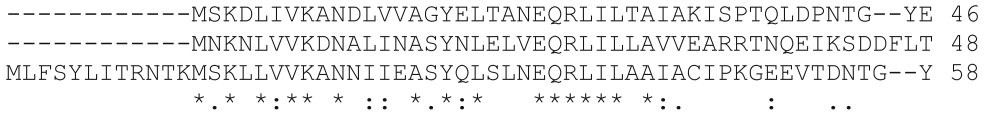
-MNKNLVVKDNALINASYNLELVEORLILLAVVEARRTNOEIKSDDFLT 48 MLFSYLITRNTKMSKLLVVKANNI IEASYQLSLNEQRLILAAIACIPKGEEVTDNTG--Y 58

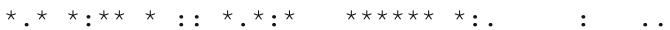

ITAKEFSKRFNIHPKTAYRELREAASRLYERS IVIKTKEQTLKARWADMIILDNP----- 101 ICAENYINEFGVHRNVAYQALKDACSHLFER----RFTYQKLTPKGNKETITSR------ 98 CVTRESFIELGVNPKTASREIREACDRLFNRVITITTEAGTFKTRWVQDIMKYNSDWALA 118

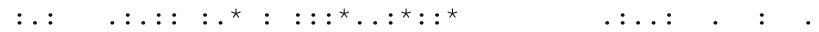

---YFEDVM----KDEDWKRVVIWFSPQVIPFLINLTENFTKYKLSEIAEFSSSYSFRIY 154 ---WVQSVS----YVENEAIVRLKF SDDVAPLITLLEKNFTSYELEQVAGLTSKYAVRLY 151 NPEFIQEVAGSDPYAEDYILAAIRFSKSVLPFISNLSSNFTQYFLQDIAGVSSGYSVRFY 178

$$
: .{ }^{\star} \quad{ }^{\star}: \text {. }:{ }^{\star} .{ }^{\star}{ }^{\star}::^{\star} .{ }^{\star \star} .{ }^{\star}{ }^{\star} .::^{\star} .:^{\star}{ }^{\star}:{ }^{\star}:{ }^{\star}
$$

EFMMQFQSTG-YIKISIKDLRERL-QLGDKYPASKDLKLWVIETAVKEINEKSPYKVDYN 212 EIIIAWRTKGRTPMFDIDELRNRLGVINDEYPRMETLKRKVIDFAVKQVNDKTDIDITYE 211 ELMMQFKSTG-YRKIRLDDLRNML-DLNNKYPLTADLKRWVIDTAIDELNEKSPITIKYK 236

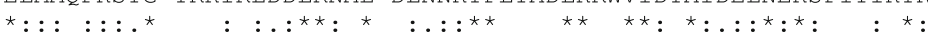

LIKTGKKFTHLELRFKQKEK-----PKPLD-QKDPNTIDIFDNLTDKERDIIAQKNAYAD 266 QHKNGRKIVGFTFVVTQKSKGKLTISKAKDKERDANTVDIFDSLTDKEREIANQKNIYAD 271 LLKTGRKFTHIELKFKQKLS-----PKKIESQRDQKTIDMFSNLSDSQIKTYSSVLSKVH 291

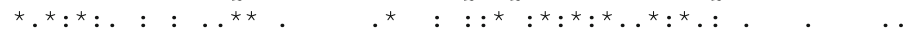

QIGATAEHRENLIRQGLTTHRQAEQDEQERKQREKAERLAQEQQDKERLELAQRQFEQIL 326 NIGAGEEHRNNLIKQALEQYRQAELETKKKKEREKAEKQAKKAKEKIELDRAKDIFEKIK 331 SISDLADNKD---YSAFAIWIANVLRDPTSVREETAKRIFKTLRTETDFKG-------- 339 ${ }^{\star}$. : : : : . : $\quad \ldots{ }^{\star} .{ }^{\star}:: \quad: \quad: \quad:$.

ASDELINAYLTHNRISEKSCFGLQKVYYQQGNFRGVFDMEKHKFEQLNYLEQLNLKFLDI 386 AEHRLINMYLARN - IDPNHLQGLQQ IRYNDGDFAGVFEMEQYKFEKLTDFRHLNLDFLQI 390 -

KQ 392

-- putative RepA protein of the pMbo4.6 was identified at position ${ }_{2668}$ TTTACA-17nt-TATAAT 2696 . Upstream of ORF3, a 320-bp intergenic region constituting the putative origin of replication that contained an AT-rich region followed by four direct repeats (DR), two 21-bp and two 22-bp, was identified (Fig. 1b). This set of repeated sequences resemble iteron structures and may play an important role in the control of plasmid replication. The direct repeats region showed high homology to the recently sequenced origins of replications of Acinetobacter plasmids (Fig. 1c). Inverted repeats (IR) and hairpin-loop structures which might confer regulatory effects on the replication of the plasmid were also noted. Analysis of this DNA fragment revealed the presence of a putative integration host factor (IHF) binding site, with high identity to the E. coli IHF consensus sequence [13], upstream of the first DR sequence (Fig. 1b). However, we did not detect sequences resembling the DnaA box. We also found that two other M. bovis strains T412 and IBA, coming 
from different geographic origins, possess plasmid similar to pMbo4.6, containing an identical oriV region (data not shown).

ORF4 encodes a 101-amino acid protein with $40 \%$ identity with hypothetical protein DUF497 found in many unrelated bacteria (BLAST). All these molecules feature the COG2929 domain, which is highly conserved in bacteria, despite there being no functions described so far for members of this family.

\section{Binding of the RepA to oriV Fragments}

To undertake pMbo4.6 RepA:DNA binding studies, the RepA protein was overproduced in E. coli BL21(DE3) cells. The RepA protein was purified by ion-exchange chromatography. SDS-PAGE revealed a clear band corresponding to a polypeptide of relative molecular weight about $45 \mathrm{kDa}$ as expected from the amino acid sequence. As the DNA target, we used fragments containing repeated sequence motifs present throughout the putative oriV region (Fig. 1b). The most striking is the presence of direct repeats which occur four times. The 7-bp inverted repeat sequences designated as IR were found within DR and repA promoter regions. The interaction between Rep and iterons is known to be crucial for the regulation of plasmid replication. For this reason, we further confirmed the binding of RepA to the oriV region by the electrophoretic mobility shift assay (EMSA). Because of the variety and number of repeats scattered over a relatively long stretch of the oriV region, a number of overlapping fragments were amplified and tested for their ability to bind RepA. First, the whole pMbo4.6 replication region (Fig. 1b) was amplified by PCR using primers orirep3 and orirep5, yielding a 378-bp DNA probe designated orirep35. EMSA were conducted with orirep35 DNA and purified RepA (Fig. 3). The RepA protein was found to bind in vitro to orirep35 DNA and the amount of the probe which was retarded appeared to be proportional to the amount of RepA added to the binding reactions. The binding of RepA was specific since the formation of the RepA-iteron was unaffected by competition with unrelated DNA. To further assess oriV functionality, EMSA were performed using PCR-generated short segments of oriV: the orirep 32 probe (184 bp) containing an AT-rich region and the orirep15 probe (186 bp) comprising four direct repeats (Materials and methods). As expected, the RepA shifted only the iteron-containing part of the oriV (data not shown).

\section{RepA-Mediated Transcriptional Autoregulation}

Analysis of the nucleotide sequence of the region located upstream of the repA gene allowed us to distinguish a putative promoter located 70-bp upstream of the start codon of repA
(Fig. 1b). A double stranded synthetic oligonucleotide containing the promoter region of the repA gene was prepared by annealing megaD and megaG oligonucleotides (Table 1) and then inserted upstream of the promoter-less reporter lacZ gene between EcoRI and $\operatorname{Bam} H I$ sites in pRS415. The resulting plasmid pRSplusIR (Fig. 4) was introduced into E. coli MC1061 cells containing resident plasmid pACYCaraRep and then $\beta$-galactosidase activity was assayed to examine promoter strength. The obtained results confirmed the presence of a strong promoter within the cloned fragment (13,094 \pm 1391 Miller units). A consistent decline of $\beta$-galactosidase activity value was observed after L-arabinose induction of the repA gene expression (Fig. 4). We also checked the level of RepA-mediated repression of expression repA gene in cells containing the promoter region without any IR sequences carried by pRSminusIR plasmid (Fig. 4 $13,753 \pm 437$ Miller units). In this case, there was no significant decrease in the RepA-dependent $\beta$-galactosidase activity level. Similarly, lack of a RepA-inhibition effect was observed for the unspecific promoter of the ecoVIIIM methyltransferases gene [25]. Also, we noticed a lower culture growth rate after arabinose addition (data not shown). This effect was observed earlier both for ara mutants (MC1061) which non-metabolize L-arabinose [6] and in the case of the induction of expression of genes from a strong promoter (i.e., ompA expressed from $P_{\text {araBAD }}$ ) [14].

\section{Discussion}

Plasmids have played a major role in the ability of bacteria to adapt to specific environmental changes. Most isolates of

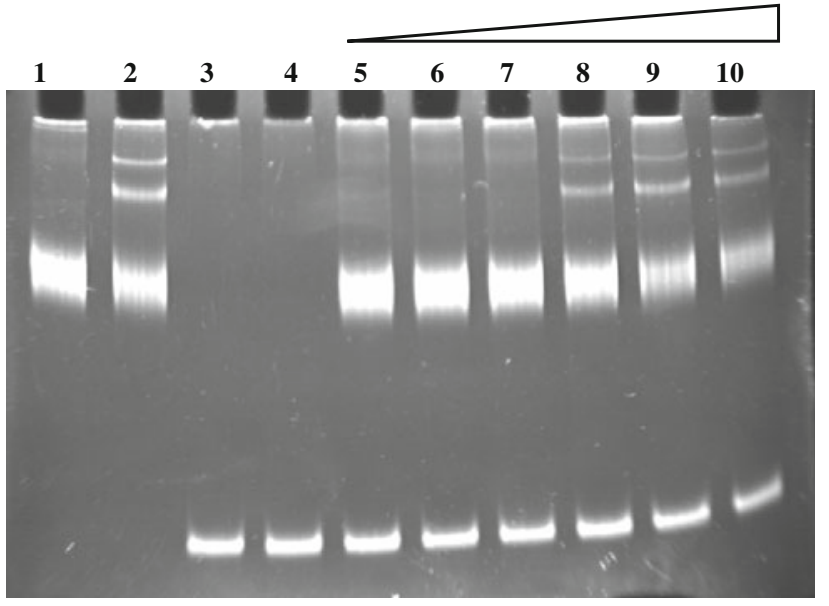

Fig. 3 Specific binding of RepA protein to the replication origin. Gel mobility shift assay using $90 \mathrm{ng}$ of orirep35 DNA fragment (378 bp), $109 \mathrm{ng}$ of competitor DNA (94 bp) and increasing amounts of purified RepA protein (50-800 ng per binding reactions) (lanes 5-10). Lanes 1 (orirep35) and 3 (competitor DNA) are negative controls without RepA protein, lanes 2 (orirep35) and 4 (competitor DNA) contain $650 \mathrm{ng}$ of RepA protein 


$$
\begin{gathered}
\text { (plusIR) GAATTCTAGGAGTATTTACAATAACTCTTTTTAGGTGTATAATTAATTACTCCTTTTTTGGATCC } \\
\text { EcoRI } \\
\begin{array}{c}
\text { BamHI } \\
\text { (minusIR) GAATTCTATTTACAATAACTCTTTTTACTCGTATAATTAATTAGGATCC }
\end{array}
\end{gathered}
$$

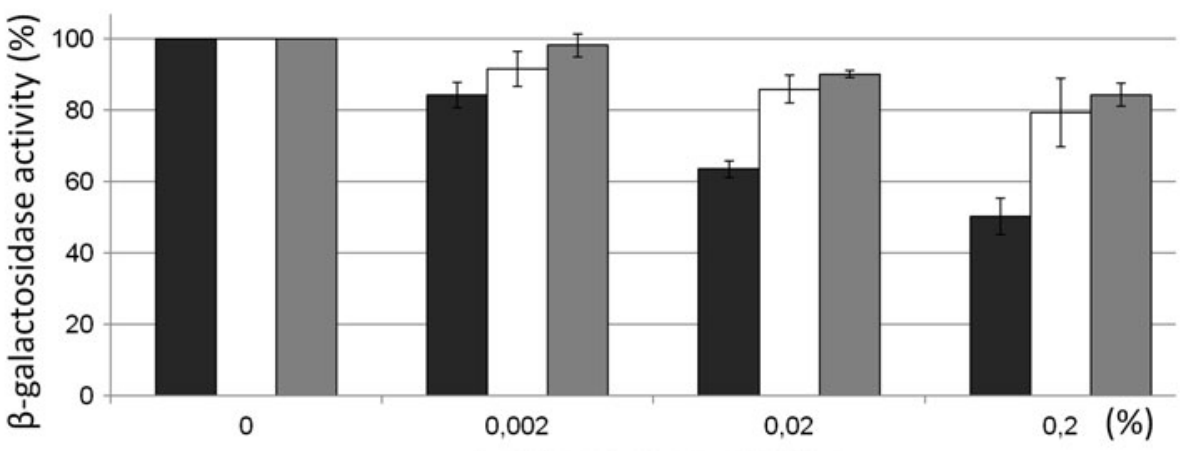

Fig. 4 Autorepression of the repA promoter. Cultures of the MC1061 strain contained derivatives of plasmid pRS415 bearing the $l a c Z^{+}$ reporter gene in transcriptional fusion with a minimal WT repA promoter fragment (pRSplusIR, black), or a mutated promoter (pRSminusIR, white) or an unspecific promoter of ecoVIIIM DNA methyltransferases (gray). $\beta$-Galactosidase activity in exponentially

M. bovis contain multiple plasmids although our knowledge concerning their functions remains limited. We discovered that the M. bovis strain ATCC 10900 harbors two plasmids of different sizes. The larger yet uncharacterized, approximately $20 \mathrm{~kb}$, was designated pMbo20, and the much smaller plasmid was sized at $4658 \mathrm{bp}$.

The data obtained from the sequence analysis suggest the presence of two modules responsible for the replication and mobilization for conjugative transfer in pMbo4.6. Such modules are commonly found in different combinations within many small plasmids residing in Gram-negative bacteria such as neisseriae [33] and Serratia marcescens ACE2 [21]. These modules also occur in some plasmids from Gram-positive bacteria: Paracoccus pantotrophus DSM 11072 [2], Enterococcus faecalis [22], and Pseudoalteromonas sp. 643A [8].

Mobilizable plasmids usually carry a mobilization gene (mob) encoding a specific relaxase and the origin of transfer (oriT) from which the initiation of conjugative transfer occurs [11]. A key role in this process is played by Mob proteins (relaxases) which mediate cleavage of the phosphodiester bond within the oriT sequence crucial for initiation of DNA transfer in both conjugative and mobilizable plasmids. Functionally, MobA proteins act by binding and nicking double stranded DNA at the origin of transfer (oriT) site ready for DNA transfer, and are responsible for re-ligating the cleaved DNA strands once the transfer of DNA is achieved. Plasmid pMbo4.6 encodes the mobilization function; however, no typical oriT consensus sequence could be found which would place it in any of the oriT-relaxase systems [12]. growing cells harboring appropriate plasmids was measured in the absence or presence of the RepA protein (pACYCaraRep), induced by a different L-arabinose concentration by $1 \mathrm{~h}$. The values obtained in the absence of induction were assumed to be $100 \%$. All values are mean \pm SD for at least three independent experiments

Rep-type proteins bind to tandem arrangements of directly repeated sequences to establish the Rep-iteron initiation nucleoprotein complex. The Rep protein of some replicons, such as pPS10 and pSC101, have an important second function; they recognize inversely repeated sequences (operators) which overlap the promoter of their own genes, acting as self-repressors [9]. This is the case in our study. IRs overlapping the repA promoter gene show a high degree of homology to those present in the iterons region. However, the RepA-dependent degree of repression of $P_{\text {repA-lac }}$ transcription obtained in our conditions was lower $(50 \%)$ than in the case of other known RepA proteins published elsewhere. We believe it is possible that the level of repression depends on the number of IR sequences present in cloned DNA fragments used in our work, similar to the results obtained for RepA from pPS10 [10]. They have shown that depending on the IRs context, the level of inhibition on the $P_{\text {repA-lac }}$ fusions changed from 30 to $88 \%$ under RepA delivery.

The essential components of the pMbo4.6 replication region were shown to be contained within a $0.3-\mathrm{kb}$ DNA segment. The identified loci has a number of features commonly found in iteron-containing plasmids including the repA transcriptional promoter $\left(P_{\text {repA }}\right)$ and an AT-rich sequence usually associated with the strand melting of the origin. Four binding sites for the RepA protein are also found centrally within the intergenic region. The location of the RepA binding sites upstream of the repA gene appears to be a common feature among this family of replicons. The number, length, and arrangement of these were not only found to be variable but also function as 
binding sites for their respective Rep proteins. Analyzing the pMbo4.6 replication origin, we found significant homology of this region to several sequences found in Acinetobacter plasmids. Each replicon contained four direct and perfectly conserved repeats and the replicase gene, suggesting a similar mechanism of replication. These plasmids have been isolated from different genera, however, as proposed by Rossau [26] and co-workers, because Moraxella and Acinetobacter are phenotypically and genotypically related they have been classified as members of the family Moraxellaceae. The presence of significantly similar sequences in different bacteria may suggest the plasmids flow through a horizontal gene transfer, phenomenon spread among members of the Acinetobacter genus [3]. We also noticed that the RepA proteins of pMbo4.6 and p2ABSDF share significant similarity. Both replicase proteins belong to the Rep-3 superfamily so it may be hypothesized that their coding sequences derive from a common ancestor. However, both plasmids were isolated from bacteria found in different and geographically separated locations which suggests that the mob genes present in both plasmids might be involved in effective genetic transfer. It is worth mentioning that both genera may easily acquisite genetic information through natural transformation, contributing significantly to bacterial adaptation in a novel environment.

Several other types of direct repeats of unknown function are also present in the region immediately upstream of the pMbo4.6 iterated region. For example, the sequence $5^{\prime}$ AACAAGAAAA $-3^{\prime}$ is repeated twice upstream of the AT reach region

Altogether, our results suggest that pMbo4.6 replicon belongs to theta replicating plasmids. The sequence analysis results revealed $m o b C$ and $m o b A$ genes as well as an inverted repeat between them suggesting that the pMbo4.6 plasmid might be mobilized in the presence of conjugative plasmids. However, further research on the characteristics of M. bovis ATCC 10900 plasmids is needed.

Acknowledgments The authors are grateful to Magdalena Serocka and Maciej Telezynski for their technical support. We also thank Martin Blaszk for his excellent help with editing this manuscript. This work was supported by the Polish Ministry of Science and Higher Education (project grants N N302 662240).

Open Access This article is distributed under the terms of the Creative Commons Attribution License which permits any use, distribution, and reproduction in any medium, provided the original author(s) and the source are credited.

\section{References}

1. Altschul SF, Madden TL, Schaffer AA, Zhang J, Zhang Z, Miller W, Lipman DJ (1997) Gapped BLAST and PSI-BLAST: a new generation of protein database search programs. Nucleic Acids Res 25:3389-3402

2. Bartosik D, Baj J, Sochnacka M, Piechucka E, Wlodarczyk M (2002) Molecular characterization of functional module of plasmid pWKS1 of Paracoccus pantotrophus DSM 11072. Microbiology 14:2847-2856

3. Bertini A, Poirel L, Mugnier PD, Villa L, Nordmann P, Carattoli A (2010) Characterization and PCR-based replicon typing of resistance plasmids in Acinetobacter baumanii. Antimicrob Agents Chemother 54:4168-4177

4. Birnboim HC, Doly J (1979) A rapid alkaline extraction procedure for screening recombinant plasmid DNA. Nucleic Acid Res $7: 1513-1523$

5. Bolivar F, Rodriguez L, Greene PJ, Betlach MC, Heyneker HL, Boyer HW, Crosa JH, Falkow S (1977) Construction and characterization of new cloning vehicles, II: a multipurpose cloning system. Gene 2:95-113

6. Casadaban MJ, Cohen SN (1980) Analysis of gene control signals by DNA fusion and cloning in Escherichia coli. J Mol Biol 138:179-207

7. Chang ACY, Cohen SN (1978) Construction and characterization of amplifiable multicopy DNA cloning vehicles derived from P15A cryptic miniplasmid. J Bacteriol 134:1141-1156

8. Cieslinski H, Werbowy K, Kur J, Turkiewicz M (2008) Molecular characterization of a cryptic plasmid from the psychrotrophic antarctic bacterium Pseudoalteromonas sp. 643A. Plasmid 60: $154-158$

9. del Solar G, Giraldo R, Ruiz-Echevarria MJ, Espinosa M, DiazOrejaz R (1998) Replication and control of circular bacterial plasmids. Microbiol Mol Biol Rev 62:434-464

10. de Viedma DG, Giraldo G, Ruiz-Echevarria MJ, Lurz R, DiazOrejas R (1995) Transcription of repA, the gene of the inhibition protein of the Pseudomonas plasmid pSP10, is autoregulated by interactions of the RepA protein at a symmetrical operator. J Mol Biol 247:211-223

11. Francia MV, Varsaki A, Garcillan-Barcia MP, Latorre A, Drainas C, de la Cruz F (2004) A classification scheme for mobilization regions of bacterial plasmids. FEMS Microbiol Rev 28:79-100

12. Furuya N, Komano T (2003) NikAB- or NikB-dependent intracellular recombination between tandemly repeated oriT sequences of plasmid R64 in plasmid or single-stranded phage vectors. J Bacteriol 18:3871-3877

13. Goodrich JA, Schwartz ML, McClure WR (1990) Searching for and predicting the activity of sites for DNA binding proteins: compilation and analysis of binding sites for Escherichia coli integration host factor (IHF). Nucleic Acids Res 18:4993-5000

14. Guzman LM, Belin D, Carson MJ, Beckwith J (1995) Tight regulation, modulation, and high-level expression by vectors containing the arabinose $\mathrm{P}_{\mathrm{BAD}}$ promoter. J Bacteriol 177: 4121-4130

15. Hanahan D (1983) Studies on transformation of Escherichia coli with plasmids. J Mol Biol 166:557-580

16. Hawley DK, McClure WR (1983) Compilation and analysis of Escherichia coli promoter DNA sequences. Nucleic Acids Res 11:2237-2255

17. Hays JP (2007) The genus Moraxella. In: Dworkin M, Falkow S, Rosenberg E, Schleifer KH, Stackebrandt E (eds) Prokaryotes, 3rd edn. Springer, Germany, pp 958-987

18. Hays JP, Eadie K, Verduin CM, Verbrugh H, van Belkum A (2005) A novel plasmid (pEMCJH03) isolated from Moraxella catarrhalis possibly useful as a cloning and expression vector within this species. Plasmid 53:263-268

19. Juni E, Heym GA, Maurer MJ, Miller ML (1987) Combined genetic transformation and nutritional assay for identification of Moraxella nonliquefaciens. J Clin Microbiol 25:1691-1694 
20. Kakuda T, Sarataphan N, Tanaka T, Takai S (2006) Filamentoushaemagglutinin-like protein genes encoded on plasmid of Moraxella bovis. Vet Microbiol 118:141-147

21. Kalibulla SI, Bakkiyaraj D, James R, Babu TG, Pandian STK (2009) Isolation and sequence analysis of a small cryptic plasmid pRK10 from corrosion inhibitor degrading strain Serratia marcescens ACE2. Plasmid 62:183-190

22. Martinez-Bueno M, Valdivia E, Galvez A, Maqueda M (2000) pS86, a new theta-replicating plasmid from Enterococcus faecalis. Curr Micriobiol 41:257-261

23. McDonald TJ, Pugh GW Jr (1986) Plasmid profiles of Moraxella bovis isolates. Am J Vet Res 47:964-966

24. Miller JH (1972) Experiments in molecular genetics. Cold Spring Harbor Laboratory Press, New York

25. Mruk I, Sektas M, Kaczorowski T (2001) Characterization of pEC156, a ColE1-type plasmid from Escherichia coli E1585-68 that carries genes of the EcoVIII restriction-modification system. Plasmid 46:128-139

26. Rossau R, van Landschoot A, Gillis M, de Ley J (1991) Taxonomy of Moraxellaceae fam. nov., a new bacterial family to accommodate the genera Moraxella, Acinetobacter, and Psychrobacter and related organisms. Int J Syst Bacteriol 41:310-319

27. Sambrook J, Fritsch EF, Maniatis T (1989) Molecular cloning, a laboratory. Manual, 2nd edn. Cold Spring Harbor Laboratory Press, New York

28. Schurig GG, Lightfoot DR, Troutt HF, Finkler BI (1984) Genotypic, phenotypic, and biological characteristics of Moraxella bovis. Am J Vet Res 45:35-39
29. Simons RW, Houman F, Kleckner N (1987) Improved single and multicopy lac-based cloning vectors for protein and operon fusion. Gene 53:85-96

30. Studier FW, Moffatt BA (1986) Use of bacteriophage T7 RNA polymerase to direct selective high-level expression of cloned genes. J Mol Biol 189:115-130

31. Thompson JD, Higgins DG, Gibson TJ (1994) CLUSTAL W: improving the sensitivity of progressive multiple sequence alingment through sequence weighting, position-specific gap penalties and weight matrix choice. Nucleic Acid Res 22:4673-4680

32. Vallenet D, Nordmann P, Barbe V et al (2008) Comparative analysis of acinetobacters: three genomes for three lifestyles. Plos One 3(3):e1805

33. van Passel MW, van der Ende A, Bart A (2006) Plasmid diversity in neisseriae. Infect Immun 74:4892-4894

34. Wallace RJ, Steingrube VA, Nash DR, Hollis DG, Flanagan C, Brown BA, Labidi A, Weaver RE (1989) BRO $\beta$-lactamases of Branhamella catarrhalis and Moraxella subgenus Moraxella, including evidence of chromosomal $\beta$-lactamase transfer by conjugation in B. catarrhalis, M. nonliquefaciens, and M. lacunata. Antimicrob Agents Chemother 33:1845-1854

35. Wilt GR, Wu G, Bird RC (1989) Characterization of the plasmids of Moraxella bovis. Am J Vet Res 50:1678-1683 